\title{
Anti -Bacterial Activity of Punica granatum Flower Extract against Several Gram-Negative and Positive Bacteria
}

\author{
Ali Ahmadi ${ }^{1}$, Neda Soleimani ${ }^{* 2}$, Parham Abedini ${ }^{1}$ \\ 1. Department of Plant Biology, Faculty of Biological Sciences, Shahid Beheshti University, Tehran, Iran. \\ 2. Department of Microbiology, Faculty of Biological Sciences, Shahid Beheshti University, Tehran, Iran.
}

\section{Article Type: \\ Original Article \\ Article History: \\ Received: 3 Nov. 2018 \\ Revised: 08 Dec. 2018 \\ Accepted: 15 Dec. 2018 \\ *Correspondence: \\ Neda Soleimani \\ Assistant Professor, \\ Department of \\ Microbiology, \\ Faculty of Biological \\ Sciences, Shahid \\ Beheshti University, \\ Tehran, Iran. \\ Email: \\ N_soleimani@sbu.ac.ir}

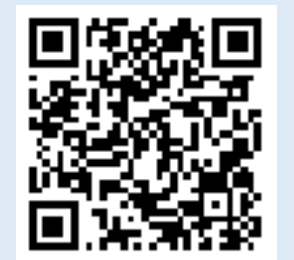

\begin{abstract}
Background and objectives: Bacterial antibiotic resistance is a major issue in the process of infectious disease treatments. The aim of this study was an evaluation of the antibacterial activity of Punica granatum flower extract against several gram-negative and positive clinical bacterial isolates.
\end{abstract}

Methods: An adequate dried flower of an endemic mature Punica granatum plant was used for extraction. The standard strain of several gram negative and positive bacteria was chosen for this study, as well as some distinguished clinical strains such as Pseudomonas aeruginosa and Enterococcus spp. In order to indicate the antibacterial effect of Punica granatum mature flower, well-diffusion method was done for each bacterium of the extraction of the flower, so that zone inhibitions can be reported. MIC and $\mathrm{MBC}$ test was done.

Results: Disc diffusion test was done and the greatest zone inhibition Shigella was 39 $\mathrm{mm}$ and then Salmonella typhimurium $13.1 \mathrm{~mm}$. The lowest antibacterial effect of P. granatum extraction was gained on Proteus with $6 \mathrm{~mm}$ of zone inhibition. The Highest $\mathrm{MIC}$ and MBC effect was obtained from antibacterial evaluation on S. typhimurium and S. epidermidis.

Conclusion: the antibacterial activities of medicinal plants, pharmaceutical companies are just using medicinal plants in association with synthetic drugs in order to obtain better results. Setting up a more analytic test on medicinal plants same as HPLC test could be the next stage of this study in order to reach to a higher reliance of medicinal plants antibacterial activities qualification So That we could combine them with synthetic drugs and improve their efficiency.

Keywords: Punica granatum; antibacterial activity; clinical isolates

\section{Introduction}

Antibiotic resistance is considered as one of the world's most pressing public health problems. Almost every type of bacteria has become stronger and less responsive to antibiotic treatment $(1,2)$. Thesis antibiotic- resistant bacteria can quickly spread to family members, schoolmates, and co-workers thus threatening the community with a new strain of infectious disease that is more difficult to cure and more expensive to treat. For this reason, antibiotic resistance is among the top concerns of the Center for Disease Control

Copyright@ 2018, Jorjani Biomedicine Journal has published this work as an open access article under the terms of the Creative Commons Attribution License (http://creativecommons.org/licenses/by-nc/4.0/) which permits noncommercial uses of the work while it is properly cited. 
(CDC) (3). If a microbe is resistant to many drugs, treating the infections it causes can become difficult or even impossible (4). Some cases with an infection that is resistant to a certain medicine can pass that resistant infection to another person. In this way, a hard-to-treat illness can be spread from person to person (5). In some cases, the illness can lead to serious disability or even death. Antibiotic usage promotes the development of antibiotic-resistant bacteria day-to-day (6). Every time a person takes antibiotics, sensitive bacteria are killed, but resistant microorganisms may be left to grow and multiply. Repeated and improper uses of antibiotics are primary causes of the increase in drug-resistant bacteria. While antibiotics should be used to treat bacterial infections, they are not effective against viral infections like the common cold, many cases of sore throat and the flu (7). Widespread use of antibiotics promotes the spread of antibiotic resistance. Natural medicines are increasingly important in treating disease. In many parts of the world natural medicines and plants are still being used as a traditional way of treatment for different diseases such as infections, diarrhea, fever, and cold. Traditional knowledge can provide a starting point in the search for plant-based medicines $(8,9)$. Punica granatum (Pomegranate, Anar, Grenade, Granaatappel, Pomo Granato) typically is a deciduous shrub tree originating from Asia. It's 5-10 meters tall with simple leaves which are usually 2-8 centimeters long. This plant is commonly multi-stemmed. Its flower and fruit are red colored but in some rare cases, orange or yellow is probable (physiology based). The root and stem barks are reported to have astringent and anthelmintic activity $(10,11)$. Several studies have demonstrated the therapeutic antioxidant, antimicrobial and antiinflammatory effects of $P$. granatum fruit, peel, and juice $(11,12)$. These effects are mainly exerted by molecules like polyphenols and tannins. In this study, we investigate the antibiotic effects of the $P$. granatum flower aqueous extract on several classes of gram negative and positive bacteria.

\section{Materials and Methods}

Punica granatum flower used in this study was prepared from it's alive mature green pomegranate plant located at North jungles in the Rasht region Persia Localized and endemic species. Collected flowers were washed carefully and then dried at the $15 \mathrm{C}$. then the dried flowers were powdered. Maceration method of extraction was used in order to release the aqueous extract. $1.5 \mathrm{~g}$ of the main powder was solved into $5 \mathrm{ml}$ of distilled water. The Concentration of the extraction used for the study was $0.3 \mathrm{~g} / \mathrm{ml}$. then the falcon was placed at a stable rack with its lid closed to be prepared for the maceration extraction process. After 24 hours the aqueous extract was released. The falcon was sterilized using an autoclave for 15 minutes at 121 centigrade. After separating the sediments, filtering, the extract was ready to use. Standard bacterial strains were obtained institute pasture in Iran and used for this study. Strain ware used sample Staphylococcus aureus ATCC 25923, Staphylococcus epidermidis ATCC 35984, Serratia spp., Salmonella typhimurium ATCC 14028, Proteus spp., Shigella spp., Klebsiella spp., Nitrobacter, Pseudomonas, Corynebacterium. as well as, some clinical distinguished bacteria strains including Pseudomonas aeruginosa (P226, P229, P127, P122, P115, P137 isolates) and Enterococcus clinical strains (E40, E35, and E46 isolates). These were separated from Shahid Mohammadi Hospital in Bandar Abbas city, Iran. 
For evaluation of the antibacterial effect, Well diffusion Method and Micro broth Dilution method was used.

Well diffusion Method was used in order to evaluate the antibacterial effects of Punica granatum flower aqueous extraction according to some study (13-15). All bacteria were subcultured in TSA. Suspension of bacteria was prepared exactly with a 0.5 McFarland standard solution. Each strain of the Bacteria was cultured at Mueller Hinton Agar (merk-Germany) by special bacterial culture for antibiogram. Then a punching was used for all media plates and then $50 \mu \mathrm{l}$ of the extract was injected to each formed wells of both Petri dishes and then incubated for $18 \mathrm{~h}$ at $37^{\circ} \mathrm{C}$.

Minimum Inhibitory Concentration (MIC) test was operated using 96 well sterile plate using Microbroth Dilution method (16-18). Extraction was diluted in Mueller Hinton broth (Merck, Germany) as media. The same value of bacteria solution $\left(1.5 .10^{6} \mathrm{CFU}\right)$ was added to each well. After incubation for $24 \mathrm{~h}$ at $37^{\circ} \mathrm{C}$, the concentration of the Latest well lacking any opacity was called MIC (22-24). As a positive control was used Gentamicin antibiotic.

\section{Results}

The results of antibacterial activity test of $P$. granatum flower extraction by well diffusion method were demonstrated in Figure 1. The results of well diffusion method showed that zone inhibition of Shigella (39 $\mathrm{mm})$, S. typhi $(13.1 \mathrm{~mm})$, S. aureus (12.9 $\mathrm{mm})$, Klebsiella $(11.9 \mathrm{~mm})$, S. epidermidis
$(11.2 \mathrm{~mm})$ and Proteus spp. $(6 \mathrm{~mm})$ respectively. S. typhi, S. aureus, Klebsiella spp. , S. epidermidis and Proteus are next in zone inhibition diameter, respectively, with Proteus noticeably having the lowest diameter. The well diffusion test was inefficient on Serratia spp. The extract was not affected on clinical isolated of bacteria were Pseudomonas aeruginosa P226, P229, P127, P122, P115, P137 and Enterococcus isolated clinical strains E40, E35, and E46.

The results of the MIC test showed that $P$. granatum flower extract had inhibitors the effect on S. Typhi and S. epidermidis. The most effect of the extract was seen in 0.038 $\mathrm{mg} / \mathrm{ml}$ Concentration on S. Typhi and S. epidermidis and then $0.075 \mathrm{mg} / \mathrm{ml}$ Concentration has inhibited the growth of other bacteria in Table 2 .

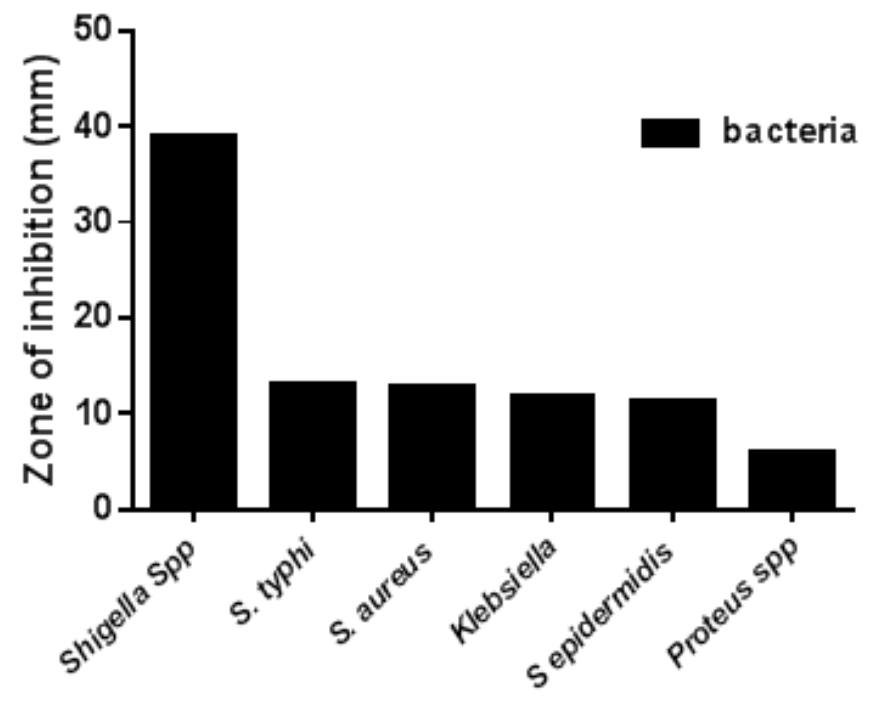

Table 1: Zone inhibition of Punica granatum flower extract against standard strains of bacteria (mm) 

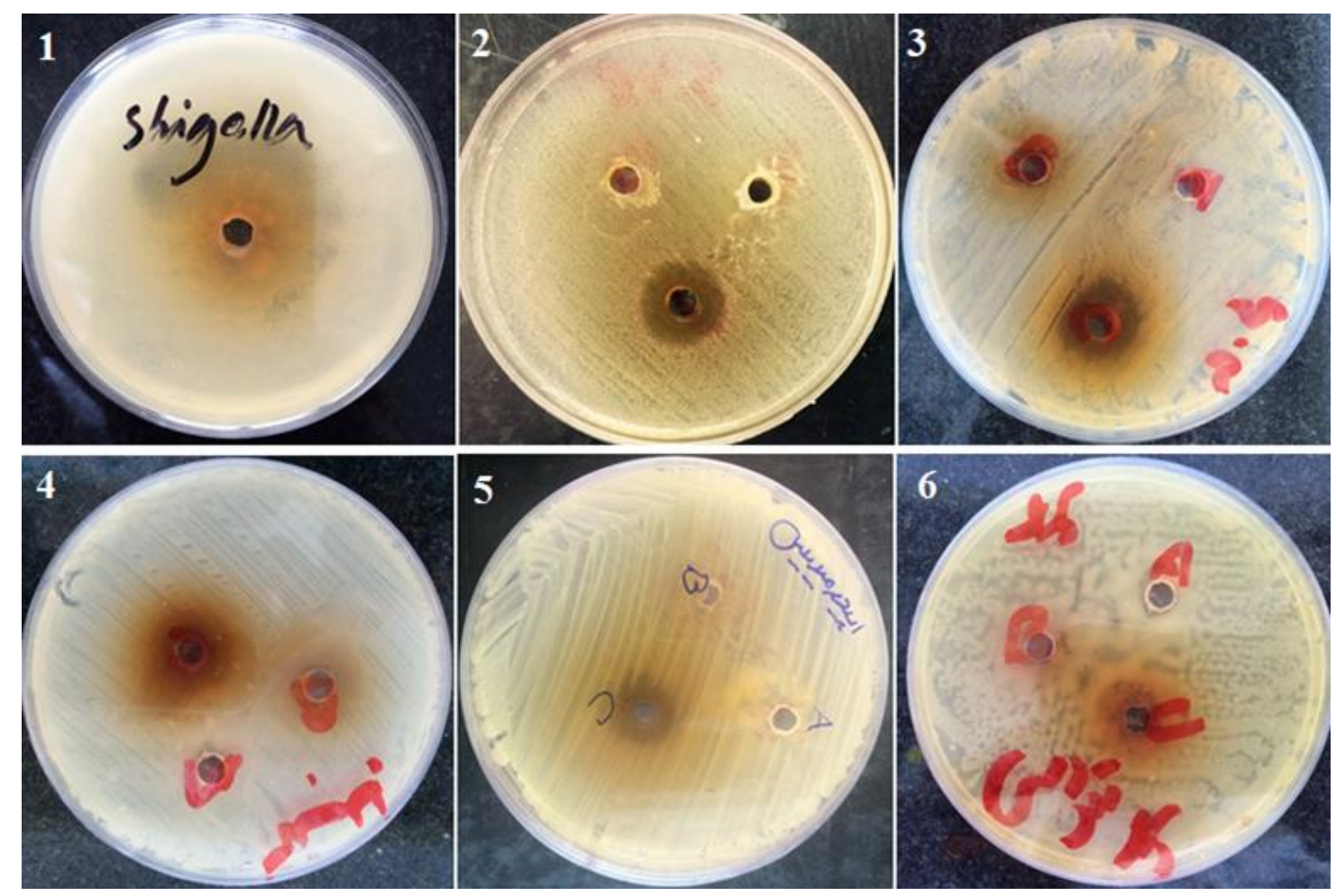

Figure 1: Zone inhibition of inhibited and Effected Bacteria in Well diffusion tests.

Table2: Results of Minimum inhibitory concentration of Punica granatum flower extraction against standard strain bacteria. The most inhibited and affected bacteria were S. Typhi and S. epidermidis equally. (-) nongrowth, (+) growth of bacteria

\begin{tabular}{lllll}
\hline Bacteria & S. typhi & S. epidermdis & S. aureus & $\begin{array}{c}\text { Klebsiella } \\
\text { spp. }\end{array}$ \\
$\begin{array}{l}\text { Concentration } \\
\text { mg/ml }\end{array}$ & & & & \\
\hline 0.150 & - & - & & - \\
\hline 0.075 & - & - & - & - \\
\hline 0.038 & - & - & + & + \\
\hline 0.019 & + & + & + & + \\
\hline 0.009 & + & + & + & + \\
\hline 0.005 & + & + & + & + \\
\hline
\end{tabular}




\section{Discussion}

In addition to edible usages of medicinal plants in traditional medical methods or using them as a flavor or garnish, they also could be used in association with chemical and synthetic products to be a preventer or a way to cure some cureless ailments. So because of the antibacterial activities of medicinal plants, pharmaceutical companies already are using medicinal plants in association with synthetic drugs in order to take better results. Dastjerdi and et al in 2014 This experimental study showed that Punica granatum flower water extract has antibacterial effects against five common oral bacteria, S. Mutans, S. saguinis, S. salivarius, S. sobrinus and E. Faecalis (19). Zone inhibition for these bacteria was 10.5 at minimum and 18 at maximum condition. In the other study on other bacteria Pasteurella haemolytica which also showed the antibacterial effects of $P$. granatum (pericarp, leaves, flowers, seeds) (20). An old study done in Delhi presented that the flower aqueous extract has antiamoebic activity against $E$. histolytica at $2 \mathrm{mg} / \mathrm{ml}$ and $4 \mathrm{mg} / \mathrm{ml}$ concentrations (21). But as there were no similar studies, there were no sources to compare this study. Results of this study directly showed that $p$. granatum flower water extract has antibacterial activity. But in order to be more sufficient, we suggest operating a comparison which this experiment should be the next step of this study. Setting up the HPLC technique analysis could help chemists to find the most effective compound which causes the antibacterial activity.

The studied extract could be a curer of minor skin infections caused by S. epidermidis. We suggest that the extract could be a skin wound healer after processing and industrialized condensation. $P$. granatum flower water extract also could be helpful in association with synthetic drugs and also it would have some synergistic effects on related synthetic drugs to cure gastric and intestinal (S. typhi) diseases causing by pathogenic activity. The extract was not affected on clinical isolated of bacteria were Pseudomonas aeruginosa and Enterococcus clinical strains. We suggested the examination was done on other clinical strain. Hospital-related infections are one of the most significant issues which always suffer medicines and people whom their lifestyle are somehow related to and involved with hospitals. Proteus is one of the bacteria which play a significant role in hospitalacquired infections. In this study we investigated the effects of $P$. granatum flower condensed extraction on Proteus and its related hospital-acquired infections. In recent years, Klebsiella has become an important pathogen in nosocomial infections. This study suggests that the water extract of $p$. granatum flower, independently or with other agents could be a healing extraction even better than synthetic drugs in comparison.

Punica granatum flower aqueous extract also could be an ideal daily drink to avoid some gastric pathogens. $P$. granatum flower aqueous extract has antibacterial effects. It had different effects on each strain of studied bacteria. This study would prepare a media of using $p$. granatum extract as an antibacterial agent especially in drug resistance cases. This extraction also can increase the efficiency of some synthetic drugs. Punica granatum flower aqueous extract also could be a drug supplement. 


\section{Acknowledgements}

None

\section{Declarations}

\section{Conflict of interest}

We declare that we have no financial or non-financial conflicts of interest related to the subject matter or materials discussed in the article.

\section{Authors' contributions}

All authors contributed equally to this work.

\section{References}

1. Rayner C, Munckhof WJ. Antibiotics currently used in the treatment of infections caused by Staphylococcus aureus. Intern Med J. 2005; 35 (2): 3-16. Review. Erratum in: Intern Med J. 2006 Feb;36(2):142-3.

2. Allen, H. K., J. Donato, H. H. Wang, K. A. Cloud-Hansen, J. E. Davies, and J. Handelsman. .Call of the wild: antibiotic resistance genes in natural environments. Nat. Rev. Microbiol. 2010: $8: 251-259$.

3. Llor C, Bjerrum L. Antimicrobial resistance: risk associated with antibiotic overuse and initiatives to reduce the problem. Ther Adv Drug Saf. 2014; 5(6): 229-241.

4. Aminov, R. I. . The role of antibiotics and antibiotic resistance in nature. Environ. Microbiol. 2009: 11:2970-2988.

5. Friedman M. Antibiotic-resistant bacteria: prevalence in food and inactivation by food-compatible compounds and plant extracts. J Agric Food Chem. 2015: 63(15):3805-22.

6. Tenover FC. Mechanisms of antimicrobial resistance in bacteria. Am $\mathrm{J}$ Infect Control. 2006; 34(5):3-10

7. Brown JC, Jiang X. Prevalence of antibiotic-resistant bacteria in herbal products. J Food Prot. 2008;71(7):148690.

8. Huang TH, Peng G, Kota BP, Li GQ, Yamahara J, Roufogalis BD, Li Y. Antidiabetic action of Punica granatum flower extract: activation of PPAR gamma and identification of an active component. Toxicol Appl Pharmacol. 2005; 1; 207 (2): 160-9.

9. Li Y, Wen S, Kota BP, Peng G, Li GQ, Yamahara J, Roufogalis BD. Punica. granatum flower extract, a potent alphaglucosidase inhibitor, improves postprandial hyperglycemia in Zucker diabetic fatty rats. J Ethnopharmacol. 2005: 3;99(2):239-44.

10. Kaur G, Jabbar Z, Athar M, Alam MS. Punica granatum (pomegranate) flower extract possesses potent antioxidant activity and abrogates Fe-NTA induced hepatotoxicity in mice. Food Chem Toxicol. 2006; 44(7):984-93.

11. Nasiri E, Hosseinimehr SJ, Akbari J, Azadbakht M, Azizi S. The Effects of Punica granatum Flower Extract on Skin Injuries Induced by Burn in Rats. Adv Pharmacol Sci. 2017;2017:3059745.

12. B. Howell A, H. D'Souza D. The Pomegranate: Effects on Bacteria and Viruses That Influence Human Health. Evid Based Complement Alternat Med. 2013; 60: 6212.

13. Daneshmandi S, Soleimani N, Pourfathollah AA, Sattari M. Evaluation of the drug synergistic and antibacterial effects of Cuminum cyminum essential oil. Arak Medical University Journal 13 (2), 75-82.

14. Zafarghandi AS, Ashtiani HRA, Rezayat SM, Soleimani N, Doost SRH,_Evaluation of Reciprocal Pharmaceutical Effects and Antibacterial Activity of Silver Nanoparticles and Methanolic Extract of Crocus sativus L.(Saffron) on Some Bacterial Strains. Int J Enteric Pathog 5 (1), 18-23. 
15. soleimani N, ebraze N. Evaluate antibacterial effects of cinnamomun verum and ferula gummosa essential oil on some pathogen gram positive and negative bacteria. New cellular \& molecular biotechnology journal. 2014: 6 (23), 8793.

16. Haghighi F, Roudbar Mohammadi S, Soleimani N, Sattari M. Evaluation of antifungal activity of essential oils of Thymus vulgaris, Petroselinum Crispum, Cuminum cyminum and Bunium persicum on candida albicans in comparison with Fluconazole Modares Journal of Medical Sciences: Pathobiology. 2010: 14 (1), 29-35.

17. Soleimani N, Sattari M, Sepehriseresht S, Daneshmandi S. Evaluation of reciprocal pharmaceutical effects and antibacterial activity of Bunium persicum essential oil against some Gram positive and Gram negative bacteria. Iran J Med Microbiol. 26-34.

18. Soleimani N, Mobarez A, Jafari Olia M, Atyabi F. Synthesis, Characterization and Effect of the Antibacterial Activity of Chitosan Nanoparticles on VancomycinResistant Enterococcus and Other Gram Negative or Gram Positive Bacteria. International Journal of Pure \& Applied Sciences \& Technology. 2015: 26(1): 1423.

19. Vahid Dastjerdi E, Abdolazimi Z, Ghazanfarian M, Amdjadi P, Kamalinejad M, Mahboubi A. Effect of Punica granatum L. Flower Water Extract on Five Common Oral Bacteria and Bacterial Biofilm Formation on Orthodontic Wire. Iran J Public Health. 2014; 43(12):168894.

20. Al Laham ShA, Al Fadel FM. The AntiBacterial Effect of Punica granatum Extracts Against Antibiotic
Resistant Pasteurella haemolytica. Jundishapur J Microbiol. 2013; 6(9): e7750.

21. antibacterial activity of rind and flowers of punica granatum linn, naqvi shAH. J Sci. I. R. Iran. 1993; 4 (1): 1-3.

22. John $M$,et al ,.In vitro Activity of cinamomum zeylanicum Against azole resistant and sensitive candida species and apilot study of cinnamon for oral candidiasis, The American Journal of Chinese medicine,January 1996,Vol.24,No.02:pp:103-109.

23. Preuss HG, Echard B, Brook I, Elliott TB. Minimum inhibitory concentrations of herbal essential oils and monolaurin for gram-positive and gram-negative bacteria. Mol Cell Biochem 2005; 272(1-2):29-34.

24. Y.ghasemi et al, Ferula gummosa Frvits:Av Aromatic Antimicrobial Agant,chemistry of natural compounds. 2005: 41 (3): 42-55.

\section{How to cite:}

Ahmadi A, Soleimani N, Abedini P. Anti -Bacterial Activity of Punica granatum Flower Extract against Several Gram-Negative and Positive Bacteria. Jorjani Biomedicine Journal. 2018; 6(4): 1-7. 